\title{
Polymer Coatings Comprised Entirely of Soft and Semi-Permeable Microcapsules
}

Curran G. Gahan, ${ }^{1, \dagger}$ Xuanrong Guo, ${ }^{1, \dagger}$ Uttam Manna, ${ }^{1, \#}$ and David M. Lynn ${ }^{1,2, *}$

${ }^{1}$ Department of Chemical \& Biological Engineering, University of Wisconsin-Madison, 1415 Engineering Dr., Madison, WI 53706 USA; 'Department of Chemistry, University of WisconsinMadison, 1101 University Ave., Madison, WI 53706 USA; ${ }^{\dagger}$ Equally contributing author; ${ }^{\#}$ Current Address: Department of Chemistry, Indian Institute of Technology-Guwahati, Guwahati, Assam-781039, India.E-Mail: (D.M.L) dlynn@engr.wisc.edu

\section{Supporting Information}
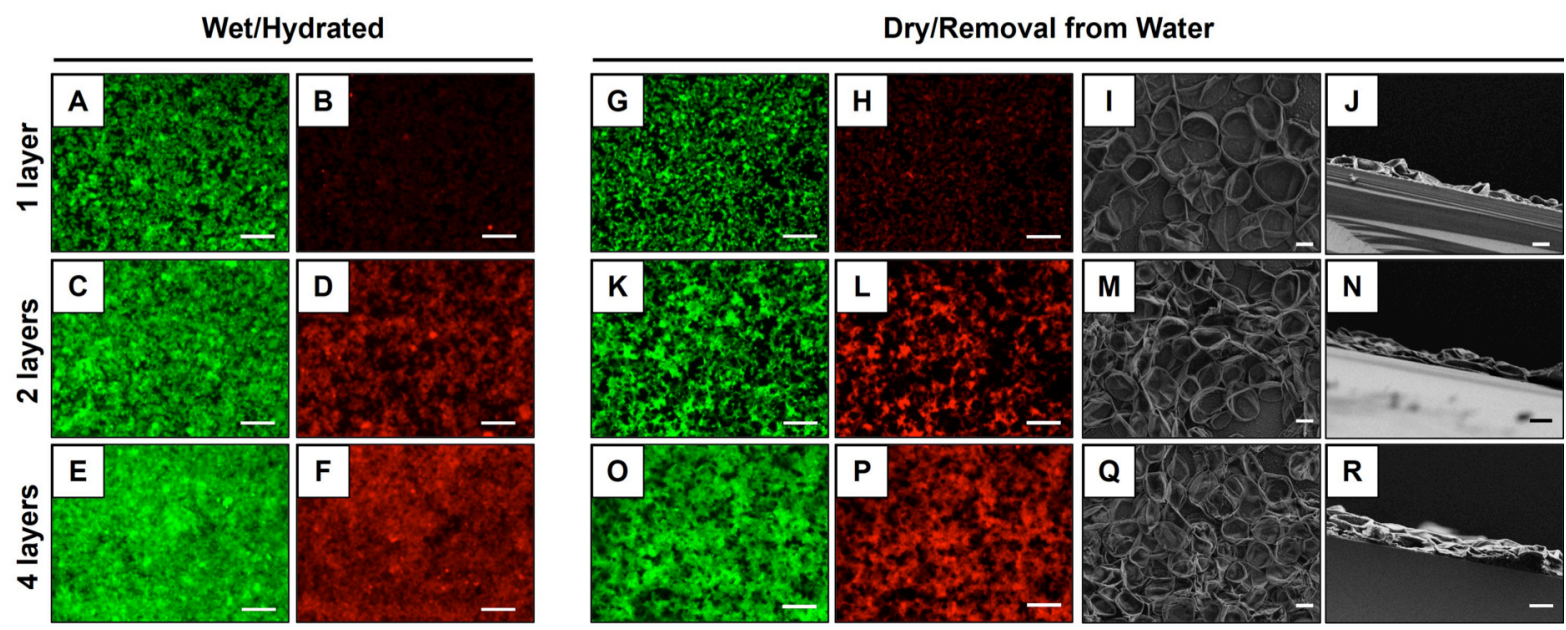

Figure S1: (A-F) Green channel (A,C,E) and red channel (B,D,F) fluorescence microscopy images of $(\mathrm{A}, \mathrm{B})$ one-layer, $(\mathrm{C}, \mathrm{D})$ two-layer, and $(\mathrm{E}, \mathrm{F})$ four-layer assemblies of aminecontaining and amine-reactive capsules hydrated in water. $(\mathrm{G}-\mathrm{R})$ Green channel $(\mathrm{G}, \mathrm{K}, \mathrm{O})$ and red channel $(\mathrm{H}, \mathrm{L}, \mathrm{P})$ fluorescence microscopy images and top-down $(\mathrm{I}, \mathrm{M}, \mathrm{Q})$ and crosssectional $(J, N, R)$ SEM images of $(\mathrm{G}-\mathrm{J})$ a one-layer, $(\mathrm{K}-\mathrm{N})$ two-layer, and $(\mathrm{O}-\mathrm{R})$ four-layer assemblies of polymer capsules dehydrated under vacuum. Scale bars are $60 \mu \mathrm{m}(\mathrm{A}-\mathrm{P})$ and 2 $\mu \mathrm{m}(\mathrm{I}-\mathrm{R})$. 

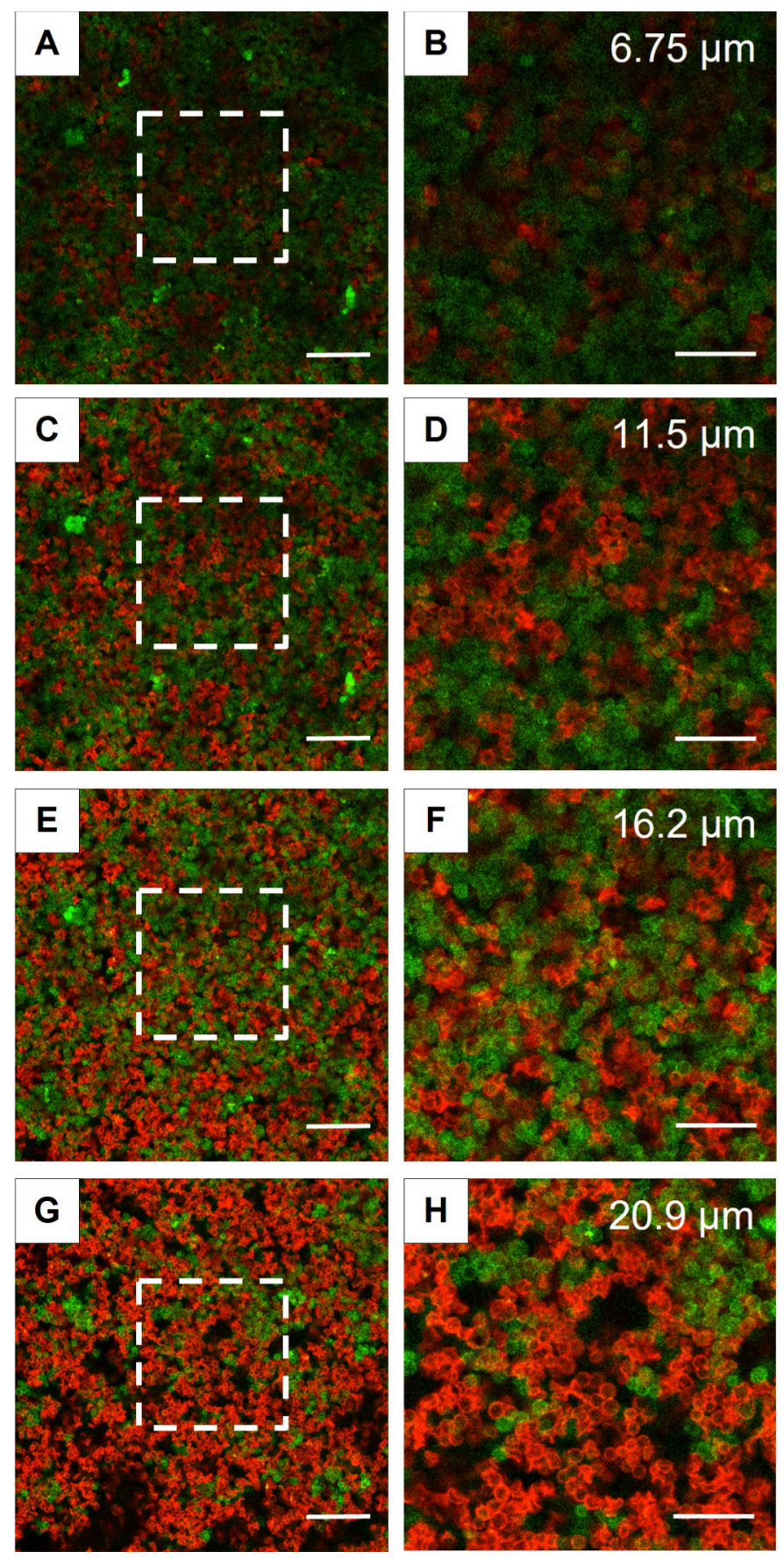

Figure S2: Confocal microscopy images of four-layer capsule assemblies acquired at different $z$-axis locations in the sample at low $(\mathrm{A}, \mathrm{C}, \mathrm{E}, \mathrm{G})$ and high $(\mathrm{B}, \mathrm{D}, \mathrm{F}, \mathrm{H})$ magnifications. The images were acquired at heights of $(\mathrm{A}, \mathrm{B}) 6.75 \mu \mathrm{m},(\mathrm{C}, \mathrm{D}) 11.5 \mu \mathrm{m},(\mathrm{E}, \mathrm{F}) 16.2 \mu \mathrm{m}$, and $(\mathrm{G}, \mathrm{H}) 20.9 \mu \mathrm{m}$ relative to the lowest $z$-position acquired (approximately the location of the film/glass substrate interface). The dashed squares on the low magnification images indicate the approximate areas shown in the higher magnification images shown to the right. Scale bars represent $50 \mu \mathrm{m}(\mathrm{A}, \mathrm{C}, \mathrm{E}, \mathrm{G})$ and $25 \mu \mathrm{m}(\mathrm{B}, \mathrm{D}, \mathrm{F}, \mathrm{H})$. 